\title{
A IMPLANTAÇÃO DE CIDADES INTELIGENTES NO NORDESTE BRASILEIRO: UM BREVE DIAGNÓSTICO
}

\section{THE IMPLEMENTATION OF INTELLIGENT CITIES IN THE BRAZILIAN NORTHEAST: A BRIEF}

DIAGNOSIS

\author{
Patrícia Borba Vilar Guimarães ${ }^{1}$ \\ Douglas da Silva Araújo ${ }^{2}$ \\ Ademir Araújo da Costa ${ }^{3}$
}

\section{RESUMO}

1 Bacharel em Direito pela Universidade Estadual da Paraíba (1997). Tecnóloga em Processamento de
Dados pela Universidade Federal da Paraíba (1989); Mestre em Direito pela Universidade Federal do Rio
Grande do Norte (2008). Mestre pelo Programa Interdisciplinar em Ciências da Sociedade, na área de
Políticas Sociais, Conflito e Regulação Social, pela Universidade Estadual da Paraíba (2002). Doutora em
Recursos Naturais pela Universidade Federal de Campina Grande (2010). É Advogada e Professora da
Universidade Federal do Rio Grande do Norte, no Departamento de Direito Processual e Propedêutica
(DEPRO). Líder da Base de pesquisa em Direito e Desenvolvimento (UFRN-CNPq) Docente vinculada ao
Programa de Pós-graduação em Direito (UFRN-Mestrado Acadêmico) e ao Programa de Pós-graduação
em Gestão de Processos Institucionais (UFRN-Mestrado Profissional). Membro do European Law Institute
(ELI). Membro da Associação Portuguesa de Direito Intelectual (APDI). Participa de atividades de
cooperação internacional diversas, com projetos em desenvolvimento com: Universidade do Porto
(UPORTO), no Centro de Investigação Jurídico-econômica (CIJE), Instituto Politécnico de Leiria (IPLEIRIA),
Universidade de Coimbra, Departamento de Altos Estudos em Direito da Universidade de Coimbra (DaED),
European Law Institute (ELI), Universidade do País Basco, Departamento de Direito Empresarial.
Universidade de la Plata, Argentina (Governo Eletrônico). Universidade de Montréal, Canadá.
Universidade Federal do Rio Grande do Norte - UFRN, Rio Grande do Norte - Brasil. Lattes: http://lattes.cnpq.br/3134219236556237 Orcid: https://orcid.org/0000-0001-9130-3901 E-mail: patriciaborb@gmail.com

${ }^{2}$ Mestre em Direito Constitucional pela Universidade Federal do Rio Grande do Norte (UFRN). Mestre em Planejamento e Dinâmicas Territoriais pela Universidade do Estado do Rio Grande do Norte (UERN). Professor DNS I da Universidade Potiguar (UnP/Laureate). Especialista em Criminologia e Segurança Pública pela Faculdade Integrada de Patos (FIP). Bacharel em Ciências Jurídicas e Sociais pela Universidade Federal de Campina Grande (2013). Membro da base de pesquisa Direito e Desenvolvimento (UFRN). Tem experiência na área de Direito Penal e Direitos Humanos, com ênfase em estudos sobre violência contra a mulher. Atualmente, desenvolve pesquisa sobre proteção de dados pessoais. Universidade Federal do Rio Grande do Norte - UFRN, Rio Grande do Norte - Brasil. ORCID iD: http://orcid.org/0000-0002-57111153.Lattes: http://lattes.cnpq.br/8845939328554043 E-mail: douglasaraujojp@gmail.com

3 Possui Graduação em Geografia pela Universidade Federal do Rio Grande do Norte (1976), Mestrado em Geografia (Geografia Humana) pela Universidade Federal do Rio de Janeiro (1991) e Doutorado em Geografia (Geografia Humana) pela Universidade Federal do Rio de Janeiro (2000). Atualmente é Professor Associado IV da Universidade Federal do Rio Grande do Norte, lotado no Departamento de Geografia, sendo professor do Programa de Pós-Graduação e Pesquisa em Geografia (UFRN) em nível de mestrado e doutorado. Tem experiência na área de Geografia, com ênfase em Geografia Urbana e Geografia do Nordeste, atuando principalmente nos seguintes temas: verticalização das cidades, crescimento urbano, impactos socioespaciais, segregação e desigualdades regionais. Universidade Federal do Rio Grande do Norte (UFRN) - Brasil. Lattes: http://lattes.cnpq.br/8382380271380702

Orcid: https://orcid.org/0000-0002-0920-0629

URL:

https://sigaa.ufrn.br/sigaa/public/docente/portal.jsf?siape=349714 E-mail: ademir@ufrnet.br 
O presente trabalho tem por objetivo analisar o resultado do 'Ranking Connected Smart Cities', relativo ao ano de 2018, em especial as informações referentes à região do Nordeste brasileiro. Para tanto, foi realizada uma análise de algumas ações viabilizadas pela cidade do Recife/PE para se tornar uma cidade inteligente, considerando a base teórico-conceitual do tema. No que diz respeito à estrutura do trabalho, inicialmente, foi feito um resgate sobre o processo de industrialização do Nordeste e como tal fato concorreu para a dinamização da sua base econômica, para o fortalecimento do mercado interno e para atrair investimentos para a região. Posteriormente, foram analisados os conceitos de cidades inteligentes, sustentáveis e digitais no intuito de estabelecer as diferenças e os pontos de convergência entre esses temas. Ao final, após a análise dos dados sobre o ranking de cidades inteligentes do Nordeste, concluiu-se que ainda há muito caminho a ser percorrido para a implantação de verdadeiras smart cities na região, não bastando ações pontuais e desintegradas para solução dos problemas urbanos com o uso da tecnologia. Projetos "smart" devem prezar pelo desenvolvimento das funções sociais da cidade (moradia, lazer, trabalho, transporte, etc.), intermediado pela tecnologia, e sempre visando à garantia do bem-estar de seus habitantes.

Palavras-chaves: Cidades inteligentes. Cidades sustentáveis. Cidades Digitais. Nordeste brasileiro. Projetos inteligentes.

\section{ABSTRACT}

The present work aims to analyze the results of the 'Connected Smart Cities Ranking', related to the year 2018, especially the information referring to the region of the Brazilian Northeast. For this, an analysis of some actions made possible by the city of Recife/PE to become an intelligent city was carried out, considering the theoretical-conceptual basis of the theme. With regard to the structure of the work, initially, a rescue was made on the industrialization process of the Northeast and how such fact contributed to the dynamization of its economic base, to the strengthening of the domestic market and to attract investments to the region. Subsequently, the concepts of smart, sustainable and digital cities were analyzed in order to establish the differences and points of convergence between these themes.In the end, after analyzing the data on the ranking of smart cities in the Northeast, it was concluded that there is still a long way to go for the implementation of real smart cities in the region, not being enough punctual and disintegrated actions to solve urban problems with the use of technology. Smart projects should be valued for the development of the social functions of the city (housing, leisure, work, 
transportation, etc.), intermediated by technology, and always aiming to guarantee the wellbeing of its inhabitants.

Keywords: Smart cities. Sustainable cities. Digital Cities. Brazilian Northeast. Smart projects.

\section{Breves considerações sobre a economia do Nordeste}

Segundo o Instituto Brasileiro de Geografia e Estatística (IBGE, 2010) o Nordeste tem extensão territorial de 1.554.257,0 quilômetros quadrados, representando terceira maior região do país. Composto pelos estados da Bahia, Pernambuco, Ceará, Sergipe, Alagoas, Paraíba, Rio Grande do Norte, Piauí e Maranhão, o Nordeste abriga 53.081.950 habitantes, segundo Censo Demográfico de 2010 , o que corresponde a $28 \%$ da população residente no Brasil. A população urbana é maioria, com percentual de 73\%. O estado da Bahia é o mais populoso (14.016.906 habitantes) e Sergipe possui a menor concentração populacional da região (2.068.017 habitantes).

Atualmente, a economia nordestina experimenta um crescente processo de desenvolvimento, recebendo indústrias dos mais variados setores, nacionais e internacionais, principalmente pela forte participação do Estado por meio dos benefícios fiscais. Destaque-se na região a indústria do petróleo, possuindo um dos principais polos petroquímicos do Brasil, localizado em Camaçari, na Bahia. A cana-de-açúcar ainda é um produto agrícola de grande importância, porém áreas de fruticultura irrigada estão em crescente expansão, além do destaque para o turismo como forte pilar econômico da região.

Nos últimos anos de expansão, algumas áreas do Nordeste adquiriram proporções crescentes no cenário econômico regional devido ao desenvolvimento de atividades advindas com o processo de industrialização da região, além da permanência das áreas tradicionais, como é o caso das zonas de cultivo de cana-de-açúcar e agropecuária. Sobre as áreas dinâmicas, Araújo (1997, p. 13) alude:

[...] importantes movimentos da economia brasileira tiveram fortes repercussões na região Nordeste nos anos recentes. Tendências da acumulação privada reforçadas pela ação estatal, quando não comandadas pelo Estado brasileiro, fizeram surgir e se desenvolver no Nordeste diversos subespaços dotados de estruturas econômicas modernas e ativas, focos de dinamismo em grande parte responsáveis pelo desempenho relativamente positivo apresentado pelas atividades econômicas na região. Tais estruturas são tratadas na literatura 
especializada ora como frentes de expansão, ora como polos dinâmicos, ora como manchas ou focos de dinamismo e até como enclaves.

Tais "frentes de expansão" ou "polos dinâmicos" compreendem o Complexo Petroquímico de Camaçari, as zonas agroindustriais de Petrolina/Juazeiro e dos cerrados do Oeste da Bahia, o parque têxtil/confecções de Fortaleza e o polo mineiro-metalúrgico CarajásSão Luís. Além de serem frutos da dinamização econômica da região, que foi resultante do período de integração econômica vivenciado pelo Nordeste, tais polos destacam-se inclusive no cenário internacional, concorrendo com outros países nos mais variados setores de produção.

Contudo, nem sempre foi assim. A história socioeconômica do nordeste foi marcada por um modelo exploratório que, em certa medida, ainda se faz presente na atualidade. Os estados nordestinos ainda ocupam as últimas colocações no ranking nacional de Índice de Desenvolvimento Humano (IDH), a taxa de mortalidade infantil ainda é a maior do país.

O Nordeste brasileiro quase sempre foi uma região associada a problemas sociais (MARTINS, 2011), apontada como área de secas e de concentração de renda por parte das oligarquias agrárias, sendo uma região de muitos contrastes (ANDRADE, 2011).

O Nordeste, com sua estrutura econômica pouco integrada, participou do processo de desenvolvimento brasileiro fornecendo força de trabalho e capital para a acumulação no CentroSul, polo dinâmico da economia nacional, sem, contudo, se beneficiar diretamente da dinamização da economia sulista (DORIGATTI JUNIOR, 2010).

Sem tanta visibilidade e arrasada pela seca vivenciada pela região em 1958, a economia nordestina começa a despertar forte preocupação do então Presidente Juscelino Kubitschek, que convocou Celso Furtado para elaboração de um programa de desenvolvimento econômico para a região.

É nesse cenário que o economista Celso Furtado, em 1959, elabora "Uma Política de Desenvolvimento Econômico para o Nordeste", também conhecido como Relatório Grupo de Trabalho para o Desenvolvimento do Nordeste (GDTN), fazendo uma análise sobre a economia nordestina, propondo planos de ação para reverter o quadro de perda de importância econômica da região a fim de torná-la menos suscetível a graves impactos gerados pelas secas no semiárido. O relatório também destacou a disparidade dos níveis de renda entre o Nordeste e o Centro-Sul e a concentração [de renda] verificada naquele; a regressividade do sistema tributário e a falta de compreensão institucional dos problemas da região, que acabavam por 
acentuá-los através de programas de industrialização que privilegiam o Centro-Sul (TOLEDO, 2013).

Celso Furtado aventava a industrialização como forma eficaz para superar o atraso relativo ao Nordeste, ressaltando a existência de um exército de subempregados na região. Para Furtado (1987) a política industrial daria emprego a essa massa flutuante, criaria uma classe dirigente nova, imbuída do espírito desenvolvimentista, além de fixar na região os capitais formados em outras atividades econômicas, que atualmente tendem a emigrar.

Em resumo, a industrialização era a saída para o Nordeste, pois daria bases para um desenvolvimento endógeno, capaz de diversificar a base produtiva, de absorver mão-de-obra, criando um mercado interno capaz e um empresariado capitalista dinâmico (IMBELLONI, 2008).

Após a elaboração do Relatório do GTDN e do seu Plano de Ação em 1959, foi aprovada, no mesmo ano, a criação da Superintendência do Desenvolvimento do Nordeste (SUDENE), completando com a estruturação de um modelo de intervenção do governo federal (central), que satisfazia os princípios desenvolvimentistas e correspondia aos anseios regionais (IMBELLONI, 2008).

A SUDENE que tinha como principal agente financeiro o BNB, dava formas concretas aos processos de integração do espaço econômico nacional, coordenando todos os programas e ações de inversões federais no Nordeste, concedendo incentivos fiscais e financeiros com vistas à atração de investimentos, planejando e executando as intervenções necessárias (UDERMAN, 2008).

A atuação de Celso Furtado à frente da SUDENE ilustra sua busca incessante de contribuir para um Nordeste menos desigual, sintetizada nas palavras de Diniz (2009, p. 237):

Resgatando a própria interpretação sobre o desenvolvimento brasileiro e a interpretação da Cepal (1950), Furtado fórmula um sintético, porém profundo, diagnóstico das razões do subdesenvolvimento nordestino e cria as bases para a sua superação. Celso Furtado buscou, através da teoria, explicar a singularidade da Região Nordeste, bem como identificar as determinantes primárias do atraso nordestino, nas formas históricas de sua ocupação econômica, na sua estrutura fundiária e não nas determinações climáticas, procurando mostrar possíveis soluções.

Portanto, a SUDENE surgira como instituição voltada a centralizar e a orientar as ações político-econômicas na região Nordeste, na tentativa de superar a dualidade que se manifestava nas relações de troca inter-regionais, com impactos sociais bastante negativos. Na proposição 
de Celso Furtado as forças dominantes do Centro-Sul do país estariam (estavam) determinadas a apoiar as iniciativas de mudanças da região, cuja modernização também beneficiaria as atividades industriais do Centro-Sul, abrindo-Ihe novos mercados (COSTA, 2016).

Dentre tantas ações da SUDENE, destaca-se a liberação de incentivos fiscais que acarretou, por exemplo, na concentração de atividades produtivas em nível regional. Entre 1963 e 1990, cerca de US\$ 6,7 bilhões foram liberados, tendo sido a Bahia, Pernambuco e Ceará os estados mais beneficiados (LIMA, 1994).

Nesse contexto, como já afirmado, pode-se perceber a importância do papel do Estado, sobretudo por meio de benefícios e incentivos fiscais, como sujeito principal do desenvolvimento do Nordeste, experimentado a partir da década de 1960, o que proporcionou uma integração econômica da região.

Recentemente, no período de 2002 a 2015, a economia do Nordeste apresentou uma expansão de suas atividades superior àquela observada na economia brasileira. O PIB regional cresceu a uma média anual de 3,3\%, enquanto o País obteve taxas médias de 2,9\%. Neste período, a participação relativa do PIB nordestino no produto nacional passou de 13,1\% para 14,2\%, atingindo seu maior percentual de participação, registrado na série "Contas Regionais", do Instituto Brasileiro de Geografia e Estatística (2017). Outros indicadores, como é o caso do IDH, também se mostraram positivos nesse último período (IBGE, 2017).

Paralelamente, diante a industrialização da região a partir da década de 1960, percebeuse uma mudança na dinâmica dos fluxos populacionais e do crescimento urbano brasileiro em direção ao centro-sul, sobretudo em razão das políticas de desenvolvimento regional direcionadas para as regiões periféricas (Norte e Nordeste) do Brasil. É a partir desse período que se desencadeia um paulatino desenvolvimento urbano no Nordeste (OLIVEIRA; MORAIS; PEREIRA, 2013), elevando o crescimento de suas grandes cidades e regiões metropolitanas.

Após essas considerações iniciais e atendendo à perspectiva deste estudo, é possível perceber como cenário do Nordeste brasileiro está propício à implantação das novas cidades inteligentes, movimento originário das novas políticas de planejamento urbano do final da década de 90, especialmente em razão dos constantes e crescentes investimentos na região, além da necessidade de criação de políticas públicas eficientes para solucionar os problemas oriundos do processo de desenvolvimento e aumento dos centros urbanos.

No tópico seguinte, será abordado o conceito das cidades inteligentes, sob uma perspectiva holística e integrada, a fim de oferecer subsídio ao objetivo central deste trabalho. 


\section{Cidades sustentáveis, digitais e inteligentes}

Antes de adentrar no debate central deste estudo, revela-se necessário, ao menos para fins didáticos, fazer algumas diferenciações sobre o que é uma cidade sustentável, uma cidade digital e uma cidade inteligente.

A cidade sustentável tem como um dos seus princípios basilares melhorar o bem estar dos cidadãos e da sociedade como um todo através da integração, do planejamento e da administração do meio urbano, que aproveita os benefícios dos sistemas ecológicos, protegendo e nutrindo esses recursos para gerações futuras (SUZUKI et al., p. , 2010).

Romero (2007, p. 51) conceitua cidade sustentável como:

[...] o assentamento humano constituído por uma sociedade com consciência de seu papel de agente transformador dos espaços e cuja relação não se dá pela razão natureza-objeto e sim por uma ação sinérgica entre prudência ecológica, eficiência energética e equidade socioespacial.

Cidades sustentáveis, nessa compreensão, objetiva um planejamento consciente das gerações atuais no que diz respeito ao uso e fruição dos recursos naturais, garantindo às gerações futuras o direito à qualidade de vida e ao meio ambiente equilibrado.

Numa acepção jurídica, o Estatuto da Cidade define cidades sustentáveis em seu art. 2o, inciso I, como "a garantia do direito a cidades sustentáveis, entendido como direito à terra urbana, à moradia, ao saneamento ambiental, à infraestrutura, ao transporte e aos serviços públicos, ao trabalho e ao lazer, para as presentes e futuras gerações".

As diretrizes contidas no Estatuto da Cidade devem ser observadas na elaboração dos instrumentos jurídicos que tratem sobre política urbana, como é o caso do plano diretor, IPTU, parcelamento, uso e ocupação do solo, zoneamento ambiental, dentre outros dispostos em seu art. 4ㅇ.

Por sua vez, uma cidade é inteligente quando o investimento em capital humano e social e a infraestrutura de comunicação (TIC) são combustíveis para o crescimento econômico e uma elevada qualidade de vida, com uma gestão racional dos recursos naturais, através de uma governança participativa (CARAGLIU; DEL BO; NIJKAMP, 2009).

As cidades inteligentes têm foco em um modelo particularizado, com visão moderna do desenvolvimento urbano e que reconhecem a crescente importância das TICs no direcionamento da competitividade econômica, sustentabilidade ambiental e qualidade de vida 
geral (DUTTA et al., 2011). Na concepção de Lijing, Yanrong e Jianhua (2014), uma cidade inteligente tem como o principal objetivo a criação de um ambiente que incentive a inovação, onde seja possível realizar a integração inteligente dos setores que envolvem a cidade. A essência da Cidade Inteligente também envolve a participação inteligente dos citadinos e o desenvolvimento sustentável local. A partir de abordagem holística, uma cidade inteligente tem por objetivo melhorar a ampla prestação de serviços usando as TICs (ALBA, 2015).

Confrontando os conceitos, uma cidade é considerada sustentável quando se desenvolve a partir de um intercâmbio saudável, respeitável e ponderável entre o meio ambiente e a geografia natural, e é inteligente quando, além disso, faz uso da tecnologia no seu cotidiano com a finalidade de solucionar suas questões diárias, integrando nelas os seus cidadãos (RIOS NETO; GIMENEZ, 2018).

A partir dos conceitos acima, verifica-se que o critério tecnológico está intrinsecamente ligado às cidades inteligentes, enquanto a questão da sustentabilidade permeia a definição de cidade sustentável, porém, como visto, também compõe o conceito das smart cities.

Então, nessa compreensão, uma cidade inteligente necessariamente também será sustentável?

Para Abdala et. al. (2014) as smart cities contribuem com as cidades sustentáveis quando a tecnologia é usada de forma inteligente, não só nas relações entre pessoas, mas também entre essas e meio ambiente, não se restringindo apenas aos interesses do mercado e devendo ser considerada sob uma perspectiva mais holística, descentralizada, integradora e participativa. Para que essa tecnologia seja utilizada a partir dessa visão, os autores ressaltam a importância da educação orientada para a sustentabilidade como umas das principais iniciativas a serem buscadas.

Para Oliveira (2018, p. 27):

Embora, hoje, a ideia de cidades inteligentes vá muito além das aplicações tecnológicas, estas ainda são fundamentais para resolver questões urbanas básicas, como, por exemplo, a geração e o uso eficiente da energia. Soluções como as malhas inteligentes de energia (smart grids) que, no fundo, representam o uso intensivo das TICs em geração, armazenamento e distribuição de energia - serão fundamentais paraque as cidades se tornem realmente sustentáveis.

Nessa acepção, o uso da inteligência (TICs) no gerenciamento das cidades (smart cities) guarda estreita relação com o conceito de cidades sustentáveis quando, além de utilizadas na 
otimização e prestação de serviços, na interação entre governo e sociedade (inclusão social), na eficiência dos processos existentes no espaço urbano, não se desvencilha da preservação e do uso moderado dos recursos naturais.

Por consequência do que foi exposto, outro questionamento agora desponta: uma cidade pode usar da tecnologia nas suas relações socioespaciais, sem, contudo, está comprometida com a questão da sustentabilidade? A resposta é sim, porém não estaria se falando mais em cidades inteligentes, e sim em cidades digitais.

Uma cidade digital tem como princípio a aplicação das Tecnologias da Informação e Comunicação (TICS) na busca de benefícios para a gestão do município e atendimento eficiente ao cidadão, englobando desde ações de democratização do acesso à internet até os mais modernos sistemas de gerenciamento de dados (FERREIRA et. al., 2017).

Para Panhan et. al. (2016, p. 25):

As cidades digitais definem uma forma de complementar a organização das cidades reais, reunindo uma vasta gama de redes digitais e softwares, os quais facilitam os múltiplos aspectos sociais e econômicos das vidas nas cidades: comércio, segurança, saúde, educação, trabalho, lazer, transporte e outros.

O conceito de cidades digitais, em ascensão na década de 1990, emergiu atualmente para as cidades inteligentes (smart cities). Quando apenas digital, o conceito era compreendido como acesso a computadores e implantação de internet no espaço urbano. Já inteligente referese aos processos informatizados sensíveis ao contexto, lidando com um incomensurável volume de dados (Big Data), redes em nuvens e comunicação autônoma entre diversos objetos e sujeitos (Internet das Coisas). A inteligência, nessa conjuntura, é sinônimo de uma cidade sensível ao meio ambiente e que lida com um grande número de informações em tempo real (LEMOS, 2013).

Como visto, as cidades digitais guardam aspectos puramente técnicos (DUTTA et al., 2011), aquém do que se entende por smart cities. Todas as cidades inteligentes são também cidades digitais, mas nem todas as cidades digitais são inteligentes (KOMNINOS, 2002). Uma das principais diferenças está na capacidade de resolver problemas das cidades inteligentes; a capacidade marcante das cidades digitais está na oferta de serviços através da comunicação digital (DETROZ; PAVEZ; VIANA, 2014). 
Weiss, Bernardes e Consoni (2013) aludem que uma cidade digital não é necessariamente inteligente, contudo ela possui componentes digitais disponíveis para gerar subsídios inteligentes.

Esse processo de "smartização" das cidades norteará as tomadas de decisões de empresas, governos e cidadãos, com o fito de tornar as atividades urbanas mais eficientes e sustentáveis nas esferas econômica, social, ecológica e política (LEMOS, 2013).

A figura abaixo tentará representar a inter-relação entre os conceitos apresentados de cidades sustentáveis, cidades inteligentes e cidades digitais:

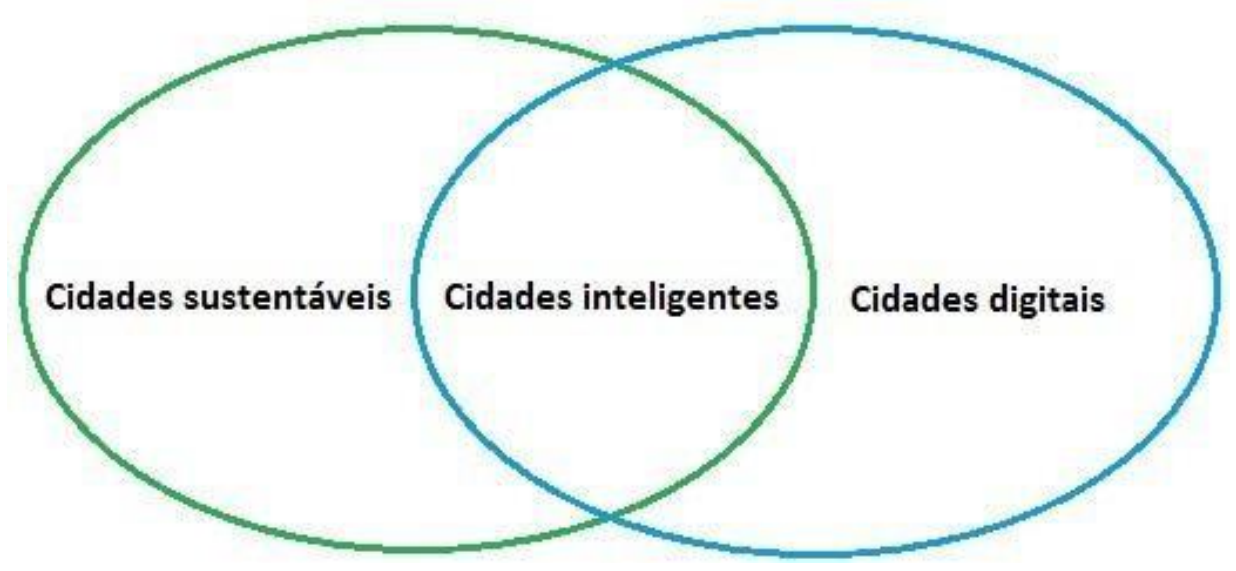

Figura 1: Cidades inteligentes. Fonte: elaborada pelos autores, 2019.

Apesar de simples, a interseção da figura representa como a fusão desses dois conceitos (cidades sustentáveis e cidades digitais) pode gerar um terceiro, a cidade inteligente; apoiada na sustentabilidade e na inovação urbana a partir do uso das TICs.

\section{Construindo cidades inteligentes no Nordeste}

Após fazer algumas considerações sobre o atual cenário econômico do Nordeste e, posteriormente, da diferenciação dos conceitos de cidades sustentáveis, inteligentes e digitais, o intuito desse tópico é verificar como os municípios do Nordeste brasileiro es tão se alinhando ao conceito de cidades inteligentes. 
Com a divulgação do Ranking Nordeste Connected Smart Cities ${ }^{4}$, relativo ao ano de 2018 e baseado em indicadores de 11 principais setores (mobilidade, urbanismo, meio ambiente, energia, tecnologia, educação, saúde, segurança, empreendedorismo, economia e governança), Recife recebeu a primeira colocação, sendo a cidade referência em tecnologia e inovação no Nordeste.

Nas áreas pesquisadas, Recife se sobressaiu nos temas da tecnologia, educação, segurança, empreendedorismo e governança. Salvador teve destaque no campo da mobilidade, Feira de Santana no urbanismo, João Pessoa no meio ambiente, Caetité/BA em energia, Sobral/CE na área da saúde e Eusébio/CE em economia (RANKING CONNECTED SMART CITIES, 2018).

Recife se destacou por possuir $14,9 \%$ das conexões de internet com velocidade superior a $34 \mathrm{mb}$, além de cobertura $4 \mathrm{G}$ oferecida por quatro empresas e $27,7 \%$ dos empregos formais exercidos por profissionais de nível superior. Destacou-se ainda na categoria educação, com 243 vagas em universidades públicas por mil habitantes acima de 18 anos, média no ENEM de 543 pontos, $94,4 \%$ dos docentes do Ensino Médio com Ensino Superior e uma hora-aula diária média de 4,6 horas, além de contar com a nota final IDEB nos anos finais de 3,9 e uma despesa municipal em educação de $\mathrm{R} \$ 456$ por habitante (RANKING CONNECTED SMART CITIES, 2018).

Apesar dos avanços, nenhuma cidade do Nordeste figurou entre os dez municípios mais bem colocados no ranking, encabeçado pela cidade de Curitiba, capital do estado do Paraná.

Assim, uma nova indagação deve ser considerada: será que realmente existem cidades inteligentes em construção no Nordeste?

Inicialmente, é essencial ter em mente que as smartcities devem priorizar projetos que visem tornar a economia, a mobilidade urbana, o meio ambiente, os cidadãos e o governo mais inteligentes, de forma integrada, como as experiências das cidades inteligentes em construção

\footnotetext{
${ }^{4}$ O Connected Smart Cities envolve empresas, entidades e governos em uma plataforma que tem por missão encontrar o DNA de inovação e melhorias para cidades mais inteligentes e conectadas umas com as outras, sejam elas pequenas ou megacidades. Foi feito com o objetivo de mapear as cidades com maior potencial de desenvolvimento no Brasil, o Ranking Connected Smart Cities trará indicadores desenvolvidos pela empresa de consultoria Urban Systems, que vão qualificar as cidades mais inteligentes do país. O ranking possibilitará uma visão mais clara com relação aos destaques e investimentos necessários nos centros urbanos brasileiros. Feito com o objetivo de mapear as cidades com maior potencial de desenvolvimento no Brasil, através de indicadores que retratam inteligência, conexão e sustentabilidade, o Ranking é composto por indicadores de 11 principais setores (mobilidade, urbanismo, meio ambiente, energia, tecnologia, educação, saúde, segurança, empreendedorismo, economia e governança). (Connected smart cities. Disponível em: <https://www.connectedsmartcities.com.br/>. Acesso em: 22 jan. 2019).
} 
como Songdo, na Coreia do Sul - onde tudo está conectado à Internet e até garrafas pet terão sensores para identificar se os moradores jogam o lixo no cesto de reciclagem correto-, Masdar, em Abu Dhabi, nos Emirados Árabes - onde painéis de energia solar irão armazenar e gerar eletricidade para toda a cidade, além da implantação de ônibus e carros elétricos. No Brasil, as cidades de Porto Alegre, no Rio de Janeiro - com o desenvolvimento de sistemas para prever possíveis desastres naturais - e em Belo Horizonte - com o monitoramento da iluminação pública, por meio de sensores que analisam a sua vida útil (LEMOS, 2013).

Perceba-se que, apesar da tecnologia está empregada em diferentes frentes, há uma integração entre elas. Isto é, há um projeto maior - de verdadeiras smart cities - por trás do mero solucionismo tecnológico.

Outra questão que se coloca é a observância desses projetos aos fundamentos que se alicerçam as smart cities, consubstanciados na utilização da tecnologia nos processos urbanos, com preservação do meio ambiente e foco no desenvolvimento humano (GUIMARÃES; XAVIER, 2016), sempre que possível, de forma conjugada.

Em outras palavras, as soluções "smart" para as cidades devem ser elaboradas dentro do planejamento estratégico, permeado pela participação popular, contudo, a urgência por melhorias urbanas, o forte poder do setor privado e a ausência de gestores preparados para entender tanto os aspectos técnicos quanto sociais desse tipo de projeto, resulta na adoção de soluções desarticuladas, restritas a situações pontuais (FIGUEIREDO, 2016), que aqui se denomina de "mero solucionismo tecnológico", bem mais próximo do que se entende por cidade digital e aquém do conceito das smart cities.

Em relação à cidade do Recife, primeira colocada da região Nordeste no ranking, após consulta realizada no site da Prefeitura, por meio de ferramenta de busca disponibilizada, verificou-se que no dia 24 de julho de 2015, o então prefeito assinou um termo de adesão da capital à Rede Brasileira de Cidades Inteligentes, durante a realização do Campus Party Recife, no Centro de Convenções de Pernambuco 5 (RECIFE - PREFEITURA DA CIDADE, 2015). Em outros resultados da pesquisa, constata-se a participação da Prefeitura do Recife, por meio de

\footnotetext{
${ }^{5}$ Com a adesão à Rede Brasileira de Cidades Inteligentes, o Recife agora participa de um seleto grupo de cidades que podem tentar captar recursos para projetos inovadores e inteligentes para a capital. O Banco Mundial e a União Europeia possuem linhas de créditos voltadas para as cidades que integram este grupo. A rede faz parte da Frente Nacional dos Prefeitos, na qual Geraldo é vice-presidente para Assuntos das Cidades Inteligentes (Prefeito assina adesão do Recife à Rede Brasileira de Cidades Inteligentes na Campus Party. Disponível em: <http://www2.recife.pe.gov.br/noticias/24/07/2015/prefeito-assinaadesao-do-recife-rede-brasileira-de-cidades-inteligentes-na>. Acesso em: 10 jan. 2019).
} 
representantes, em eventos sobre a temática de cidades inteligentes (Smart City Business America Congress \& Expo 2018, Fórum Connected Smart Cities).

Em notícia veiculada em 05 de setembro de 2018, que tratava sobre o desempenho da cidade no ranking Connected Smart Cities 2018, o então Secretário Municipal de Desenvolvimento Sustentável e Meio Ambiente, ressaltou que o resultado do ranking comprova que a cidade está no caminho certo, tendo definido ações para melhorar a qualidade de vida da população, como o Parque Capibaribe, a Faixa Azul e o investimento na qualificação. Destacou também a importância da transparência na gestão, além da desburocratização do ambiente de negócios, que já reduziu o tempo para formalização de novas empresas de 100 dias para 72 horas (RECIFE - PREFEITURA DA CIDADE, 2015).

É inegável que tais avanços reforçam a tentativa da cidade de Recife em se tornar uma smart city. Contudo, como já afirmado, não bastam ações pontuais e desarticuladas para que uma cidade seja considerada inteligente. Por exemplo, apesar de Recife se destacar em conexões de internet, cobertura $4 G$ e qualidade do nível superior de ensino, não foram encontradas iniciativas por parte do Poder Público local de disponibilização de internet às camadas sociais menos desfavorecidas. Noutro ponto, apesar da qualidade de ensino ser uma condicionante para uma cidade ser inteligente, é certo que o ensino superior não é de competência do Gestor Municipal, cabendo a este tratar sobre o ensino básico.

Ao que deixa transparecer, é que as iniciativas até então tomadas são frutos da própria atividade-fim de algumas empresas, startups, como é o caso das empresas de telefonia ao vender seus pacotes de internet, do que mesmo um papel ativo por parte do Poder Executivo Municipal.

Não se pode perder de vista a importância do protagonismo do Poder Público no desenvolvimento de projetos de cidades inteligentes a partir do desenvolvimento das funções sociais da cidade (moradia, lazer, trabalho, transporte etc.), intermediado pela tecnologia, e sempre visando garantia do bem-estar de seus habitantes, conforme preleciona o art. 182 da Constituição Federal.

Sobre essa perspectiva integrativa da tecnologia às funções sociais da cidade, alude Camacho (2018, n.p.):

Com a consolidação das TICs como instrumento de integração espacial e de comunicações, governos, e agências públicas em todos os níveis estão adotando a noção de inteligência para distinguir suas novas políticas, estratégias e programas na direção de um desenvolvimento sustentável, 
um crescimento econômico sólido e melhor qualidade de vida aos seus cidadãos.

Nesse sentido, aliar a tecnologia (TICS) às funções sociais da cidade é o passo inicial para a consolidação de smart cities.

No que diz respeito ao protagonismo do Poder Público na viabilização e edificação de smart cities, algumas sugestões são: conceder redução de ITPU sobre imóveis a fim de adequar as construções urbanas a parâmetros sustentáveis (RIONDET-COSTA; SANT'ANNA; ALEXANDRINO, 2016), realizar um zoneamento urbanístico- ambiental (Lei n. 10.257/01 Estatuto da Cidade) com a finalidade de averiguar a utilização adequada das propriedades privadas, planejar o crescimento ordenado da cidade (GOMES; ZAMBAM, 2018); capacitar profissionais ligados à administração pública, com a formação de uma equipe multissetorial apta a planejar e monitorar o processo de construção de uma cidade inteligente (PALIOLOGO; GOMES, 2017), dentre outras iniciativas.

Voltando à análise do ranking, entre os 100 municípios divulgados pelo estudo, apenas nove deles estão no Nordeste, conforme quadro abaixo:

\begin{tabular}{|c|c|c|}
\hline \multicolumn{2}{|c|}{ Posição } & \multirow{2}{*}{ Município (UF) } \\
\hline 2018 & 2017 & \\
\hline $13 ㅇ$ & 10 은 & Recife (PE) \\
\hline 170 & 170 & Salvador (BA) \\
\hline 220 & 290 & Fortaleza (CE) \\
\hline 360 & 470 & João Pessoa (PB) \\
\hline 430 & 970 & Campina Grande (PB) \\
\hline 440 & 460 & Teresina $(\mathrm{PI})$ \\
\hline $82^{\circ}$ & 710 & Natal (RN) \\
\hline 83 & 940 & Aracaju (SE) \\
\hline $92 \circ$ & - & Petrolina (PE) \\
\hline 98 & - & Sobral (CE) \\
\hline
\end{tabular}

Fonte: Ranking Connected Smart Cities, 2018.

Apesar de figurar em primeiro lugar na região Nordeste, vê-se uma queda de três posições da cidade do Recife no ranking nacional entre 2017 e 2018. Salvador manteve-se na 
mesma colocação, Fortaleza caiu sete posições, João Pessoa e Aracaju subiram onze posições, Teresina subiu duas, enquanto Natal caiu onze posições.

Destaque para Petrolina/PE e Sobral/CE que figuraram pela primeira vez no ranking, e para Campina Grande/PB que subiu cinquenta e quatro posições, passando da 97ạ para 43ạ colocação.

\section{A consolidação de cidades inteligentes a partir de instrumentos normativos: o caso da cidade do Recife}

Como já observado, Recife encabeça o ranking de cidade inteligentes no Nordeste. Além das políticas, ações e programas que estão sendo desenvolvidos pela cidade no intuito de erigir uma verdadeira smart city, necessária a análise de instrumentos normativos criados pelo Poder Público dentro dessa perspectiva.

A Lei n.o 18.502/2018 ${ }^{6}$, que tratou sobre as diretrizes para elaboração e execução da Lei Orçamentária de 2019, trouxe prioridades e metas da Administração Pública Municipal, dentre elas:

Art. 3‥ A Administração Municipal, assim entendidos os órgãos que integram o Poder Executivo e respectiva Administração Indireta, inclusive a Fundacional, estabelece para 2019 as seguintes prioridades e metas, por eixo de atuação

$[\ldots]$

XIII - gestão pública: aprimorar o processo colaborativo de construção de um novo modelo de cidade inteligente e sustentável, "com a participação dos espaços de controle social", por diversos canais de comunicação, garantir transparência na divulgação e acesso às informações, otimizar os mecanismos de gestão, dando continuidade ao programa de captação de receitas adicionais e controle e redução de despesas e realizar a melhoria da gestão fiscal buscando a justiça fiscal.

Perceba-se, a partir do dispositivo acima, a importância de o aspecto desenvolvimentista das cidades inteligentes relacionar-se com a capacidade de promover uma gestão urbana atenta aos novos anseios da população influenciada pela globalização econômica,

\footnotetext{
6 Leis Municipais - Pernambuco - Recife. Lei n.o 18.502/2018. Disponível em: <https://leismunicipais.com.br/a/pe/r/recife/lei-ordinaria/2018/1850/18502/lei-ordinaria-n-185022018-dispoe-sobre-as-diretrizes-para-elaboracao-e-execucao-da-lei-orcamentaria-de-2019>. Acesso em 01 mai. 2020.
} 
sob um modo de governança compartilhada e transparente, a partir do uso das tecnologias de informação e comunicação.

Assim, depreende-se que no processo de "smartização" de uma cidade é imprescindível a inclusão dos cidadãos nos processos decisórios (smart governance), de modo a implementar uma gestão pública participativa, com a tecnologia funcionando como uma espécie de "ponte" de aproximação entre Poder Público e a população.

A lei, ainda no seu artigo 3ำ, tratou de outras ações como metas à Administração Pública, dividindo por áreas. Para o planejamento e ordenamento urbano, a Lei estabeleceu a necessidade de revisão do Plano Diretor do Recife, a fim de promover a reapropriação dos espaços públicos pela população, a requalificação do centro da cidade, o estabelecimento de novos padrões urbanísticos e a garantia da conservação do patrimônio construído. No aspecto da mobilidade, o Município pretende estimular e viabilizar deslocamentos a pé e de bicicleta considerando as diretrizes e metas do Plano de Mobilidade Urbana do Recife e do Plano Diretor Cicloviário; estimular e melhorar o transporte coletivo por meio do Programa Faixa Azul; melhorar e expandir os serviços de integração intermodal, melhorar e expandir as escadarias dos morros e córregos, melhorar a gestão e a estrutura viárias, com foco em soluções de médio e longo prazo, visando à implantação e recuperação de pavimentação, solução de pontos de alagamento, iluminação e sinalização. Para o meio ambiente, são focos a recuperação do rio que corta a cidade, a redução de emissão de gases poluentes, a ampliação de áreas verdes e espaços livres públicos, o fomento junto à indústria da construção civil a implementação em seu processo construtivo de elementos de sustentabilidade ambiental, com prática do reuso e da reciclagem. Para a habitação, a ampliação da oferta habitacional, requalificar os espaços urbanos, estimulando a moradia nas áreas centrais da cidade e promover a regularização fundiária com atenção ao Plano Diretor, fortalecendo a urbanização e a regularização das Zonas Especiais de Interesse Social (ZEIS), áreas de risco ou em condições insalubres.

Para além desses setores, a norma ainda previu metas e mudanças para a integração metropolitana, educação, saúde, a segurança, assistência social, esporte, proteção e defesa animal, direitos humanos, desenvolvimento econômico, cultura e comunicação pública.

Não há dúvida sobre o caráter promissor da Lei, especialmente pelas mudanças estruturais em quase todos os setores de serviço, econômicos e sociais, resta aguardar como o Município buscará implementar tais medidas nos próximos anos. É inegável ainda que a Lei 18.502/2018 representa um marco não só para o tema das cidades inteligentes, como também para as óticas sustentáveis, resilientes, ecologicamente corretas, desses espaços urbanos. 
Vê-se ainda a imprescindibilidade da revisão de diplomas legais, a exemplo de Planos Diretores, Habitacionais, de Zoneamento, muitas vezes defasados e incapazes de atender às normas demandas oriundas do processo de globalização e da difusão da tecnologia nos mais variados setores urbanos.

\section{Conclusão}

Dessa breve análise, é possível concluir que, apesar da conjuntura socioeconômica do Nordeste ter mudado consideravelmente nos últimos anos, especialmente após o processo de industrialização, é fato que a região ainda sofre com vários problemas de ordem socioeconômica ${ }^{7}$ (empregos informais, segundo menor rendimento médio mensal domiciliar per capita do país, população em situação de pobreza, etc.) (IBGE, 2017).

$\mathrm{Na}$ perspectiva da construção de cidades inteligentes, apenas nove municípios do Nordeste estão entre as 100 cidades que figuraram no Ranking Connected Smart Cities - 2018 (Recife/PE, Salvador/BA, Fortaleza/CE, João Pessoa/PB, Campina Grande/PB, Teresina/PI, Natal/RN, Aracaju/SE, Petrolina/PE e Sobral/CE).

As iniciativas dessas cidades ainda são pontuais e desintegradas. Alta qualidade e cobertura de internet não necessariamente quer dizer que uma cidade está no caminho para se tornar uma cidade inteligente.

A tecnologia é o fator mais característico das smart cities, porém deverá ser usada em benefício dos cidadãos, intermediando sua relação com o Poder Público, desburocratizando e otimizando a prestação de serviços, com respeito ao meio ambiente e aos dados pessoais.

Enxerga-se também a necessidade de integração dos projetos desenvolvidos nos mais variados setores de uma cidade, que poderiam ser acompanhados por meio da uma espécie de "centro" ou "observatório", para não se perder de vista as iniciativas públicas ou privadas desenvolvidas no âmbito de um Município.

Especificamente sobre a cidade do Recife, que figurou em primeiro lugar no Ranking Connected Smart Cities 2018, é possível perceber que, apesar de embrionária a ideia de cidade inteligente que vem sendo capitaneada pelo Poder Público local, um passo importantíssimo foi

\footnotetext{
7 Síntese de Indicadores Sociais. Agência IBGE Notícias. Disponível em: <https://agenciadenoticias.ibge.gov.br/agencia-sala-de-imprensa/2013-agencia-deoticias/releases/23298-sintese-de-indicadores-sociais-indicadores-apontam-aumento-da-pobreza-entre2016-e-2017>. Acesso em 18 jan. 2019.
} 
dado com a edição da Lei $n$. o 18.502/2018, que estabeleceu metas pretenciosas à todos os setores urbanos para os próximos anos.

Registre-se que a revisão de instrumentos normativos, como o Plano Diretor, é essencial para acolher essa concepção de smart city (cidade inteligente), que despontou nos anos 90 com um movimento que defende novas políticas de planejamento urbano, intermediadas pela tecnologia.

Por fim, outro ponto importante é a inclusão do setor privado na construção de cidades inteligentes, seja através de convênios ou parcerias com o Poder Público, propiciando novos modelos de gestão e de gerenciamento de pessoas e processos. Concentrar todos os esforços na Administração Pública talvez inviabilize a prestação eficiente de serviços, o incremento da gestão com uso das TIC's, a otimização da infraestrutura, essenciais quando se debate sobre cidades inteligentes, que podem ser arquitetadas com a colaboração de diferentes atores econômicos, como o próprio setor privado.

\section{Referências}

ABDALA, L.; SCHREINER, T.; COSTA, E. M.; SANTOS, N. Como as cidades inteligentes contribuem para o desenvolvimento de cidades sustentáveis? Uma revisão sistemática de literatura. Int. J. Knowl. Eng. Manag, v. 3, n.5, p. 98-120, 2014.

ALBA, Enrique. Intelligent systems for smart cities. 1. Madrid, 2015. Intelligent systems for smart cities/New York: Gecco Companion, 2015. p. 707-722.

ANDRADE, Manoel Correia de. A terra e o homem no Nordeste: Contribuição ao estudo da questão agrária no Nordeste. São Paulo: Cortez, 2011.

ARAÚJO, Tânica Bacelar. Herança de diferenciação e futuro de fragmentação. Estudos Avançados vol. 11, n.o 29, São Paulo, Jan./Abr. 1997. Disponível em:

<http://dx.doi.org/10.1590/S0103-40141997000100002> Acesso em: 02 jan. 2019.

BRASIL. INSTITUTO BRASILEIRO DE GEOGRAFIA E ESTATÍSTICA - IBGE, Síntese do panorama da economia brasileira, 2017. Disponível em: <www.ibge.gov.br>. Acesso em: 02 jan. 2019.

BRASIL. INSTITUTO BRASILEIRO DE GEOGRAFIA E ESTATíSTICA - IBGE. Censo de 2010.

Disponível em:

<http://www.ibge.gov.br/home/estatistica/populacao/censo2010/default.shtm>. Acesso em: 22 jan. 2019.

CAMACHO, José Fernando. Cidades inteligentes: um caminho à equidade do desenvolvimento urbano no século XXI? Mundo Urbano. Universidad Nacional de Quilmes. Número: 50. 2018. Disponível em: <http://www.mundourbano.unq.edu.ar/index.php/ano- 
2018/285-cidades-inteligentes-um-caminho-a-equidade-no-desenvolvimento-urbano-noseculo-xxi>. Acesso em: 02 jan. 2019.

CARAGLIU, A., DEL BO, C., NIJKAMP, P. Smart cities in Europe. Serie Research Memoranda (VU University Amsterdam, Faculty of Economics, Business Administration and Econometrics), 2009.

COSTA, Milene Ribas da. O Estado e a SUDENE : trajetória do planejamento regional no Brasil. Tese de Doutorado - Universidade Estadual de Campinas. Repositório da Produção Científica e Intelectual da Unicamp. Campinas, São Paulo, 2016. Disponível em:

<http://repositorio.unicamp.br/jspui/handle/REPOSIP/322687>. Acesso em: 02 jan. 2019.

DETROZ, Djessica; Cristienne; PAVEZ, Magalhaes Pereira; VIANA, Anna Paula. Cidades

Sustentáveis, Inteligentes e Inclusivas: reinvenção das cidades. Revista de Extensão e Iniciação Científica - REIS: 2014. Disponível em: <https://docplayer.com.br/17237948-Cidadessustentaveis-inteligentes-e-inclusivas-reinvencao-das-cidades.html>. Acesso em: 02 jan. 2019.

DINIZ, Clélio Campolina. Celso Furtado e o desenvolvimento regional. In Nova Economia, vol.19 no 2 Belo Horizonte, 2009.

DORIGATTI JUNIOR, Osmar Asdrubal. Nordeste, um estudo da estrutura econômico-social da região. 2010. 1으-ROM. Trabalho de conclusão de curso (bacharelado - Ciências Econômicas) - Universidade Estadual Paulista, Faculdade de Ciências e Letras de Araraquara, 2010.

Disponível em: <http://hdl.handle.net/11449/118914>. Acesso em: 02 jan. 2019.

DUTTA, S. et al. The Global Innovation Index 2011: accelating growth and development. Fontainebleau: INSEAD, 2011.

FIGUEIREDO, G. M. P. Cidades inteligentes no contexto brasileiro: a importância de uma reflexão crítica. In: IV ENANPARQ - Encontro da Associação Nacional de Pesquisa e Pósgraduação em Arquitetura e Urbanismo, 2016, Porto Alegre. Anais do IV ENANPARQ. Porto Alegre: PROPAR/UFRGS, 2016. Disponível em: <https://www.anparq.org.br/dvd-enanparq4/SESSAO\%2044/S44-04-FIGUEIREDO,\%20G.pdf>. Acesso em: 20 jan. 2019.

FERREIRA, Miter Mayer de Oliveira; MATOS, Maykon da Silva; ZANATA, Igor Martins; MATTOS, André Rubim. Cidade digital, o primeiro passo para um cidade inteligente e humana: um estudo de caso no município de Cachoeiro do Itapemirim. Revista Ambiente Acadêmico (ISSN Impresso 2447-7273, ISSN online 2526-0286), v. 3, n. 1, ano 2017. Disponível em: <https://goo.gl/utgvUS>. Acesso em: 02 jan. 2019.

FURTADO, Celso. Transformação e crise na economia mundial. São Paulo: Paz e Terra, 1987.

GOMES, Daniela; ZAMBAM, Neuro José. Sustentabilidade do espaço urbano: novas tecnologias e políticas públicas urbanístico-ambientais. Revista de Direito da Cidade, v. 10, n. 1, p. 310-334, jan. 2018. Disponível em: <https://www.e-

publicacoes.uerj.br/index.php/rdc/article/view/29866>. Acesso em: 25 jan. 2019.

GUIMARÃES, Patrícia Borba Vilar; XAVIER, Yanko. M. de Alencar. Smart cities e Direito:

conceitos e parâmetros de Investigação da governança urbana contemporânea. Direito da 
Cidade, v. 8, p. 1362-1380, 2016. Disponível em: <https://www.e-

publicacoes.uerj.br/index.php/rdc/article/view/26871)>. Acesso em: 12 jan. 2019.

KOMNINOS, N. Intelligent Cities: Innovation, knowledge systems and digital spaces, London and New York, Routledge. 2002.

IMBELLONI, Rosa Maria. Paradigmas do desenvolvimento no Nordeste: Do GTDN (Grupo de Trabalho para o Desenvolvimento Econômico do Nordeste) ao GTI (Grupo de Trabalho Interministerial para recriação da SUDENE). Dissertação de Mestrado - Serviço Social. Universidade Federal de Pernambuco. Repositório Institucional da UFPE. Publicação: 31-Jan2008. Disponível em: <https://repositorio.ufpe.br/handle/123456789/9515>. Acesso em: 02 jan. 2019.

LEMOS. André. Cidades inteligentes. GVexecutivo, v. 12, n. 2, p. 46-49, 2013. Disponível em: $<$ http://bibliotecadigital.fgv.br/ojs/index.php/gvexecutivo/article/view/20720>. Acesso em: 02 jan. 2019.

LIJING, Zhang.; YANRONG, Pang; JIANHUA, Huang. The Development Strategy for the Tourism in Hebei under the Background of Smart City Based on Data Mining. In: 7TH INTERNATIONAL CONFERENCE ON INTELLIGENT COMPUTATION TECHNOLOGY AND AUTOMATION. Anais [...], 1, 2014. p. 991- 994. Disponível em: < https://ieeexplore.ieee.org/document/7003701>. Acesso em: 01 mai. 2020.

LIMA, Policarpo. Economia do Nordeste: tendências recentes das áreas dinâmicas. Análise Econômica, ano 12, n. 21-22, mar./set. 1994. Disponível em:

<https://seer.ufrgs.br/AnaliseEconomica/article/view/10490>. Acesso em: 20 jan. 2019.

MARTINS, André Luiz de Miranda. Visões da "insuficiência": o nordeste e o desenvolvimento regional no pensamento social brasileiro. Revista IEB n. 52, set./mar. 2011, p. 69-88.

OLIVEIRA, Aline Alves; MORAIS, Ana Cristina dos Santos; PEREIRA, William Eufrásio Nunes. 0 processo de industrialização e urbanização da região metropolitana do Cariri: Análise das cidades de Crato, Juazeiro do Norte e Barbalha. IV Seminário Internacional sobre Desenvolvimento Regional - Rio Grande do Sul, 2013. Disponível em: <https://goo.gl/X8RCAj>. Acesso em: 20 jan. 2019.

OLIVEIRA, José Palazzo Moreira. Cidades inteligentes e sustentáveis. Apresentação oral. XXXVIII Congresso da Sociedade Brasileira de Computação. Computação e Sustentabilidade. 22 a 26 de julho de 2018. Natal/RN. Disponível em: <https://www.palazzo.pro.br/Wordpress/?p=5583>. Acesso em 21 jan. 2019.

PALIOLOGO, Nicholas Arena; GOMES, Daniel Machado. Direito à cidade e políticas públicas para a smart city. Revista de Direito Urbanístico, Cidade e Alteridade; e-ISSN: 2525-989X; Brasília; v. 3, n. 1, p. 19-35, 2017. Disponível em:<http://indexlaw.org/index.php/revistaDireitoUrbanistico/article/view/1922/pdf>. Acesso em 21 jan. 2019.

PANHAN, A. M.; MENDES, L. D. S.; BREDA, G. D. Construindo Cidades Inteligentes. 1. ed. Curitiba: Appris, v. 1, 2016. 
PREFEITURA do Recife. Disponível em: <http://www2.recife.pe.gov.br/>. Acesso em 21 jan. 2019.

RIONDET-COSTA; D. R. T.; SANT'ANNA, D. O.; ALEXANDRINO, S. A. Incentivos Legais às Construções Urbanas Sustentáveis. Direito da Cidade, v. 8, n. 4, 1381-1402. 2016. Disponível em: <https://www.e-publicacoes.uerj.br/index.php/rdc/article/view/23578>. Acesso em 21 jan. 2019.

RIOS NETO, José Vieira; GIMENEZ, Edson Josias Cruz. Cidades Inteligentes: sua contribuição para o desenvolvimento urbano sustentável. VII Seminário de Redes e Sistemas de Telecomunicações (SRST). Instituto Nacional de Telecomunicações (INATEL). ISSN 2358-1913 Setembro de 2018. Disponível em: <https://goo.gl/PAik9W>. Acesso em: 20 jan. 2019.

ROMERO, Marta A. B.. (2007). Frentes do Urbano para a Construção de Indicadores de Sustentabilidade Intra Urbana. In Paranoá: cadernos de arquitetura e urbanismo da FAU-UnB. Ano 6, n. 4 (novembro/2007). - Brasília: FAU UnB.

SUZUKI, H., DASTUR, A., MOFFATT, S., YABUKI, N., MARUYAMA, H. (2010). Eco2 Cities Ecological Cities as Economic Cities. The World Bank. Disponível em:

<https://doi.org/10.1596/978-0-8213-8046-8>. Acesso em: 20 jan. 2019.

TOLEDO, Pedro Henrique Vieira Martins. O GTDN e a SUDENE de Furtado no desenvolvimento econômico do Nordeste: concepção e realidade. Monografia de Bacharelado - Ciências Econômicas. Universidade Federal do Rio de Janeiro. Publicação: Dez. 2013. Repositório Institucional da UFRJ. Disponível em: <http://hdl.handle.net/11422/1718>. Acesso em: 02 jan. 2019.

UDERMAN, Simone. Políticas de Desenvolvimento Regional no Brasil: limites de uma nova agenda para o Nordeste. In: Associação Brasileira de estudos regionais e urbanos, vol. 2, no 2, p. 104-12, out. 2008. Disponível em: <https://www.revistaaber.org.br/rberu/article/view/23>. Acesso em: 02 jan. 2019.

WEISS, Marcos Cesar; BERNARDES, Roberto Carlos; CONSONI, Flávia Luciane. Cidades inteligentes: a aplicação das tecnologias de informação e comunicação para a gestão de centros urbanos. Revista Tecnologia e Sociedade; ISSN: 1984-3526; v. 9, n. 18; 2013. Disponível em: <https://periodicos.utfpr.edu.br/rts/article/view/2634>. Acesso em: 18 jan. 2019.

Trabalho enviado em 05 de fevereiro de 2019 Aceito em 07 de maio de 2020 